\title{
SPECIAL FEATURE
}

\section{A new joint publication}

Generally, a blunt definition of waste in the early 1980s was "A moveable object that has no direct use and is discarded permanently." Today, waste is no longer permanently discarded material, because much of it is now reusable and recyclable as an energy resource.

Asia and the Pacific region have been the fastest-growing parts of the world. Along with growth, this area has also vastly increased its need for energy and raw materials, contributing to price increases on world markets. The increased demand has led to natural resource depletion as well as to environmental degradation, straining the absorption limits of the region's ecosystems. In particular, the strong demand for fossil fuels has become a major driver of climate change. The coming decades will no doubt witness increased pressures on countries in the region to shift to resource-efficient and low-carbon production patterns as part of global efforts to slow the pace of climate change and environmental degradation.

Both the Japan Society of Material Cycles and Waste Management (JSMCWM) and the Korea Society of Waste Management (KSWM) have long been interested in green growth concepts to improve the eco-efficiency of consumption patterns and demand side management, which have now become equally important to the Japanese and Korean governments alongside the supply and production of basic goods and services. The JSMCWM and the KSWM have been closely allied for a long time as the two societies have encouraged activities such as attendance at meetings, mutual visits for study and research, and joint research seminars. Their joint publication now of a journal in English is a result of the fostering of cooperation and joint activities between the JSMCWM and KSWM. I believe the journal serves not only as an international publication but also attests to the closely linked relationship of the two societies.

Material Cycles and Waste Management has been published since 1998 and is recognized as a leading environmen-
Waste Management Research in Korea

tal journal. For the most part, it comprises a dialogue and debate among academic researchers and reports the activities of experts in the recycling of materials, the treatment of wastes, and energy recovery. The journal presents new thinking, research, and debate on the treatment and storage of waste.

The current issue has been prepared by members of the Special Working Group of the Japan and Korea Waste Management societies for the publication of the journal. The JSMCWM and KSWM hereby agreed to continue their cooperation with a view toward promoting academic interchange, thus contributing to the development and propagation of knowledge and mutual understanding between the two societies.

Before closing, I would like to thank the Special Working Group members for their interest in and dedicated work for this issue. I also thank professors Kazuo Yamamoto, Soo-Koo Lee, Sung-Keun Bae, Toshiaki Yoshioka, and Weon-Joon Lee, and the publisher, Springer Japan.

I would especially like to express my gratitude to Professor Shin-ichi Sakai, who has communicated with me numerous times by e-mail with regard to the journal. I very much appreciate his great and devoted assistance for the past 2 years.

Finally, I am very pleased to announce the launch of our joint Japan-Korea publication of Material Cycles and Waste Management with this special issue. I hope that the JSMCWM and KSWM continue to promote cooperation and advance friendship throughout the world.

JAI-YOUNG LEE
Chief Editor, Korea
JMCWM
July 1, 2009 